\title{
Gender Mainstreaming in HIV Vaccine Trials in India Meeta Singh*‡
}

Address: Women's Resource Centre, Rajasthan State Institute of Public Administration(Jaipur, IND)

* Corresponding author ‡Presenting author

from 2005 International Meeting of The Institute of Human Virology

Baltimore, USA, 29 August - 2 September 2005

Published: 8 December 2005

Retrovirology 2005, 2(SuppI I):P90 doi: I0.I I86/1742-4690-2-SI-P90

\section{Background}

In India, in December 2000, for the first time in the history of the country, the Ministry of Health and Indian Council of Medical Research signed a memorandum with International Aids Vaccine Initiative (IAVI) a non profit, non government international organization to construct and evaluate appropriate vaccines.

Today nearly 1 percent (approximately 4.5 million) of the Indian population is infected with HIV, where one in every four cases is a woman. Only 4 out of 10 women of the reproductive age group have heard of AIDS. A large percentage of girls are married by age 16 . Yet, tradition dictates that girls are not supposed to know anything about contraception or sex. When infected with HIV, women face greater stigma and rejection than men, because of the association of HIV infection with socially and morally "disapproved" behaviors in society.

Taking in view the socio cultural context of the country, considerable effort and planning is required to ensure equitable number of women participate in trials and stay through the entire duration of trial. Gender specific issues are integral to and an essential pillar of a larger programme focus on ethics. This includes building a gender sensitive perspective in members of the ethics review committee and members of the team that will be conducting the trials.

\section{Material and methods}

The National AIDS Research Institute, Pune is the nodal agency conducting the phase I trials. To ensure the mainstreaming of a gender perspective as an ethics issue in the HIV vaccine trials in India, individuals and organizations involved in running the vaccine trials are being trained to incorporate a gender perspective in planning and execut- ing every stage of the trial. This training includes those directly involved in trials as well as norm setting bodies.

\section{Results}

The participants of the training are oriented to a gender analysis framework, which enhances understanding of gender implications of the vaccine trial.

\section{Conclusion}

The framework serves as a guideline to conduct the first ever HIV vaccine trials in India, and will feed into a global blueprint guide to gender sensitive HIV vaccine trials in other countries. This training on gender issues in HIV/ AIDS helps in integrating a gender perspective in the larger issue of ethics that make up the guiding principle of HIV vaccine trials. 